\title{
Effect of Cooling of Medium on Fruit Set in High-bench Strawberry Culture
}

\author{
Takashi Ikeda ${ }^{1,2}$, Keisuke Yamazaki, Hiroshi Kumakura, and \\ Hiroshi Hamamoto \\ National Agricultural Research Center for Western Region, Ayabe, Kyoto \\ 623-0035, Japan
}

Additional index words. forcing culture, primary axillary branch, flower bud emergence

\begin{abstract}
We demonstrated the effect of cooling of the medium on the fruit set of strawberries (Fragaria $\times$ ananassa Duch.) grown on high benches for forcing culture. The cooling by water evaporation promoted by a fan enabled to cool the medium by an average of several degrees compared with no cooling. When runner plants were transplanted in late summer, cooling accelerated flower bud emergence almost 10 days on the primary axillary branch compared with plants grown in uncooled medium. Also, with cooling, fruit was harvested from the inflorescence of the primary axillary branch almost 10 days earlier. We expect that this technique will allow early transplanting around the end of summer and will shorten the time between fruit set on the terminal inflorescence and that on the inflorescence of the primary axillary branch.
\end{abstract}

Japanese growers begin planting strawberry runners for forcing culture in late summer to harvest the fruit within the year (Morishita et al., 1997). In this case, these runner plants need to be stored under refrigeration for a few weeks in total darkness or subjected to short-day treatment to promote flower-bud initiation before they are transplanted to field or culture systems (Morishita et al., 1997; Yamasaki et al., 2003). However, this flower-bud initiation is occasionally suspended and vegetative growth is restarted when temperature of the crown is kept relatively high just after transplanting (Kumakura and Shishido, 1995). Furthermore, in high-bench culture, the temperature of the culture medium tends to be higher than that of soil in a field and reversion to vegetative growth is therefore even more likely to occur. To solve this problem, we designed a high-bench strawberry culture system that uses the latent heat of water evaporation to cool the culture medium (Ikeda et al., 2006). In 2003, we showed that the maximum temperature difference between the cooled and uncooled culture media was $10^{\circ} \mathrm{C}$ (Ikeda et al., 2006). In the present study, we demonstrated that practical use of this medium-cooling system from early transplanting in late summer in 2003 and 2005 accelerated fruit growth on the primary axillary branch, which differentiates after transplanting.

\footnotetext{
Received for publication 15 July 2006. Accepted for publication 8 Sept. 2006.

We thank Mr. T. Iwamoto, Mr. Z. Obana, Mr. T. Okada, and Ms. K. Otsuki for technical assistance. ${ }^{1}$ Current address: School of Agriculture, Meiji University, Kawasaki, Kanagawa 214-8571 Japan. ${ }^{2}$ To whom reprint requests should be addressed; e-mail tikeda@affrc.go.jp.
}

\section{Materials and Methods}

High-bench culture with medium cooling. The high-bench culture system was constructed of plastic film bags on a framework (Ikeda et al., 2006). The film bag containing the culture medium was composed of two layers: an inner layer of silver-colored plastic film and an outer layer of cotton cloth. During the day, the cotton layer was keep wet by dripping water from the framework. The heat of the culture medium evaporated the water from the cotton surface of the bags, and the culture medium was cooled by the latent heat of water evaporation (Ikeda et al., 2006). Underneath the culture system, a polyethylene duct connected to a fan (Ka-120 Nepon, Tokyo) allowed more water to evaporate from the cotton.

The culture medium contained carbonized chaff and peatmoss (Majestic, Agawam, Mass.) in a ratio of 1:1. Water for irrigation of the culture medium was supplied by a line different from that used for medium cooling. Initially, $15 \mathrm{~g}$ slow-release fertilizer (Rongutotaru, $13.0 \mathrm{~N}-10.8 \mathrm{P}-4.8 \mathrm{~K}$; JA, Tokyo) and $10 \mathrm{~g}$ of lime (JA) per runner plant were contained in the culture medium. Irrigation water was supplied to the culture medium twice a day during the experiment. In the 2003 experiment, the excess irrigated water was drained off, but in the 2005 experiment, we modified the system to reuse it. The $\mathrm{pH}$ of the drainage in the 2005 experiment was kept 5.5 by addition of potassium hydroxide. We supplied liquid fertilizer (Otsuka Chemical Co. Ltd., Osaka, Japan) as necessary. The high-bench culture system was constructed in an arched plastic-film greenhouse.

We designed two regimes: dripping water with fan cooling and control (no water and no fan). Water was supplied to the cotton cloth during the day (from 6 AM to 6 PM) between 4 Sept. and 3 Oct. 2003 and between 2 Sept. and 30 Sept. 2005. The fan operated over the same period. The temperature of the medium was determined by thermocouples placed $5 \mathrm{~cm}$ below the surface (medium depth was $10 \mathrm{~cm}$ ) and recorded by a data logger (Solac III MP090; Eko Instrument Co. Ltd., Tokyo).

Plant materials. Pot-grown strawberry (Fragaria $\times$ ananassa Duch. cv. Sachinoka) runner plants with four leaves were used. In the 2003 experiment, they were stored in a growth cabinet in total darkness at $15{ }^{\circ} \mathrm{C}$ for $15 \mathrm{~d}$ (total darkness treatment) and were then transplanted into the culture system on 4 Sept. We examined 16 runner plants for each treatment. In the 2005 experiment, the plants were stored in a growth cabinet in the dark for $16 \mathrm{~h}$ at $15{ }^{\circ} \mathrm{C}$ and then kept in a shaded greenhouse for $8 \mathrm{~h}$ during the day ( $8 \mathrm{Am}$ to 4 PM) for $20 \mathrm{~d}$ (short-day treatment) and transplanted into the system on 2 Sept. We examined 58 runner plants for each treatment. Honeybees were used for pollination. The numbers of flowers were fixed to 11 for the terminal inflorescence and nine for the inflorescence of the primary axillary branch in the 2003 experiment. In the 2005 experiment, the numbers were fixed to nine and seven, respectively.

\section{Results}

Figure 1 shows the temperatures in the greenhouse and in the culture medium in the (A) 2003 and (B) 2005 experiments. All data are the means of temperatures taken hourly from 7 AM to 6 PM each day. The temperature of the control medium was always higher than that of the cooled medium. Because the greenhouse was covered by thin shadecloth in the 2005 experiment for 2 weeks after transplant, the temperature of the control medium was lower than that in the 2003 experiment.

Flower bud emergence on the primary axillary branches under the cooling regime was always faster than in the controls in the 2003 experiment (Fig. 2A). The emergence rate was $38 \%$ in the controls and $63 \%$ under cooling regime on 14 Nov. Flower bud emergence reached $100 \%$ on 17 Nov. with cooling but did not reach this value until 25 Nov. in the controls. In the 2005 experiment, on 1 Dec., the percentage flower bud emergence under the cooled regime was $62 \%$, but in the controls, it was only $33 \%$ (Fig. 2B). Under the cooling regime $80 \%$ emergence was reached on 7 Dec., but in the controls, it was not reached until 15 Dec.

After the fruits of the terminal inflorescence had been harvested from November to the beginning of January, harvesting of the fruits of the primary axillary lateral branch of the controls in the 2003 experiment started on 23 Jan., but under the cooling regime, it began on 16 Jan. (Fig. 3A). The harvest of the two regimes was almost $7 \mathrm{~d}$ apart with the same quantity of fruits being harvested (Fig. $3 \mathrm{~A}$; e.g., to reach for two fruits, on $30 \mathrm{Jan}$. for the cooling regime but on $6 \mathrm{Feb}$. for the control). In 2005, the harvest showed a maximum 17-d difference (Fig. 3B; e.g., to reach for two fruits, on $25 \mathrm{Feb}$. for the cooling regime but on 14 Mar. for the control). 


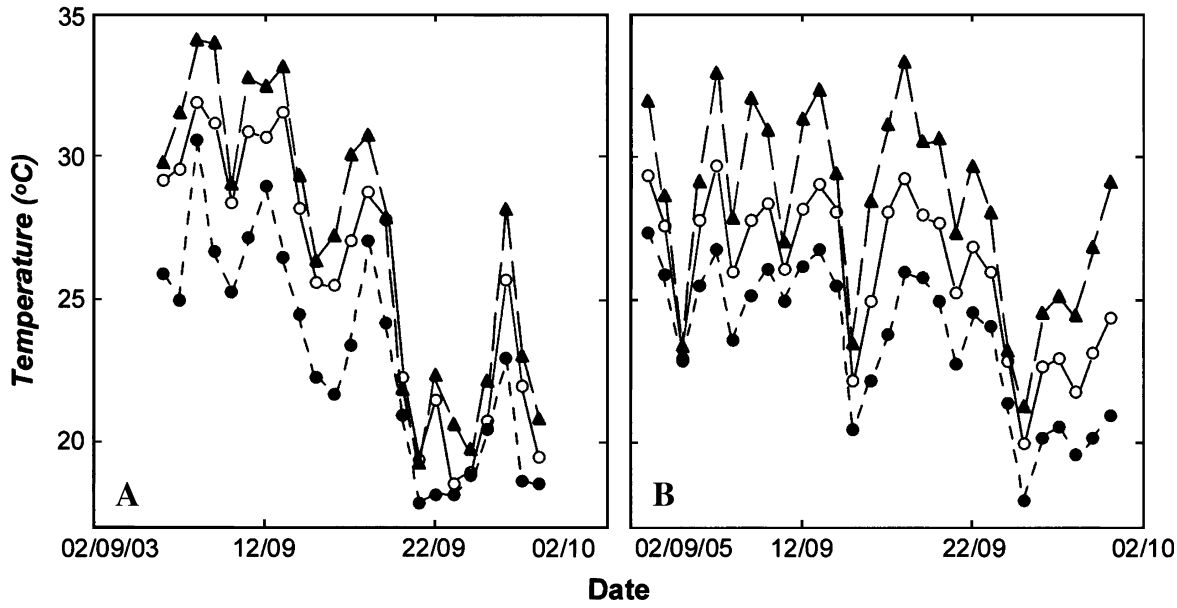

Fig. 1. Daily changes in temperatures of greenhouse air ( $\boldsymbol{\Delta})$; medium cooled by water and fan $(\boldsymbol{O})$; and control (uncooled) medium $(\bigcirc)$ in the (A) 2003 and (B) 2005 experiments. Strawberry runner plants were transplanted on 4 Sept. 2003 and 2 Sept. 2005 into the culture system. Each symbol is the mean of temperatures taken on the hour from $7 \mathrm{AM}$ to $6 \mathrm{PM}$ each day. The temperature of the medium was determined by thermocouples placed $5 \mathrm{~cm}$ below the surface of the medium. Data are the averages of determinations from three (2003) and 12 (2005) thermocouples.

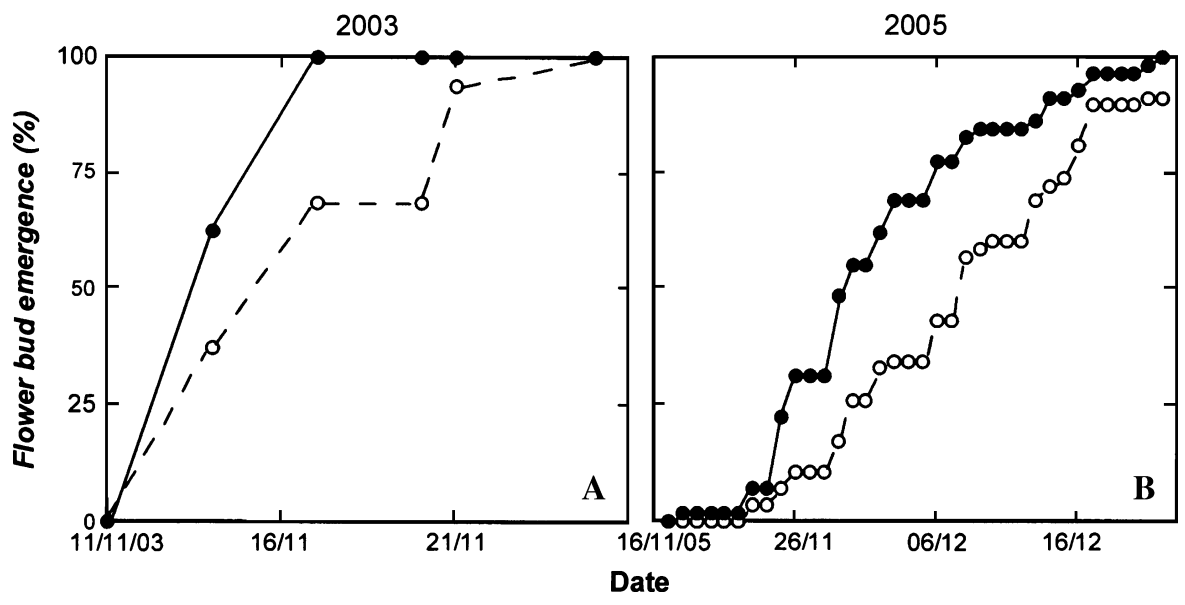

Fig. 2. Rates of flower bud emergence on the primary axillary branch of plants in medium cooled by water and fan (O) and in the control (uncooled) medium (O) in the (A) 2003 and (B) 2005 experiments. We examined 16 runner plants for each treatment in the 2003 experiment and 58 runner plants for each treatment in the 2005 experiment.

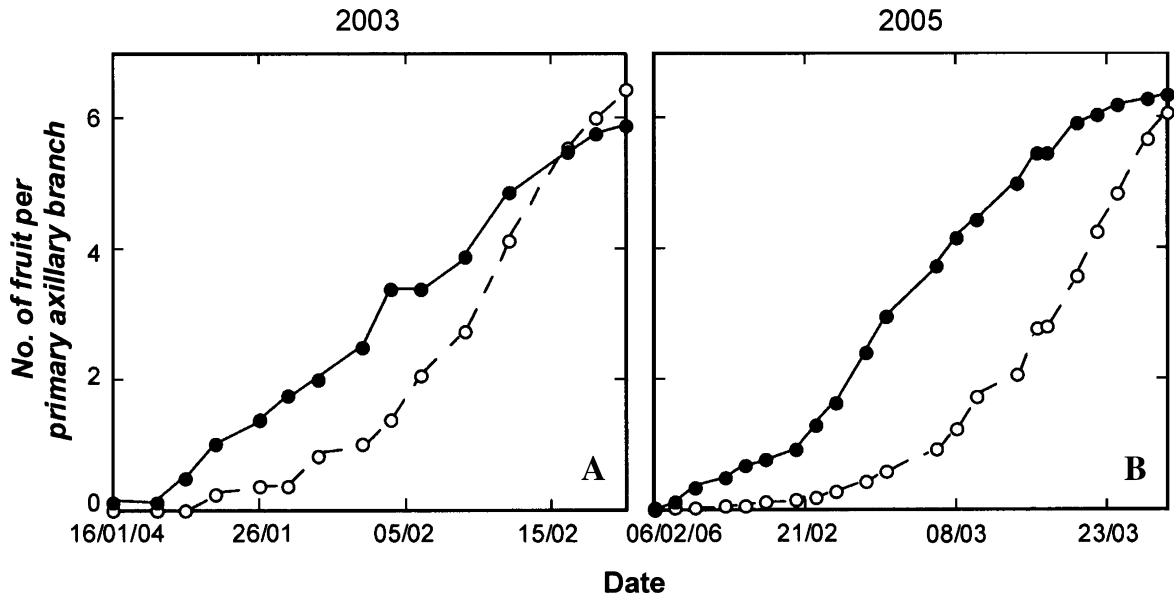

Fig. 3. Number of fruits on the primary axillary branch of each runner plant in the medium cooled by water and fan (O) and in the control (uncooled) medium (O) in the (A) 2003 and (B) 2005 experiments. We examined 16 runner plants in each treatment in the 2003 experiment and 58 runner plants in each treatment in the 2005 experiment. The number of flowers on the primary axillary branch was fixed to nine in the 2003 experiment and seven in the 2005 experiment.
The use of high-bench strawberry culture is increasing in Japan because it saves labor and can reduce the likelihood of problems with soil-borne diseases. Our cooling system for high-bench culture reduced the temperature of the culture medium (Fig. 1). Although the temperature of the medium never dropped below the wet bulb air temperature of the greenhouse, theoretically (Takaichi et al., 2001), the decrease in temperature was enough to accelerate flower-bud emergence and fruit set on the primary axillary branch. Because induction of flowering on the primary axillary branch presumably started during the cooling operation, flower-bud emergence on this branch was maybe faster than in the controls (Fig. 2). The flower-bud emergence and harvesting times of fruits of the terminal inflorescence did not differ between the regimes in the 2003 and 2005 experiments (data not shown), presumably because flower bud initiation on the terminal inflorescence had already started during cold storage (i.e., flower bud induction treatment). Because there were no duration of flower bud emergence on the terminal inflorescence (data not shown), it might have been possible to transplant the runner plants into the cooled system earlier (e.g., in late August). If so, this could give a greater marketing advantage to growers. Also, if cooling were to be used even earlier in spring again, it might be possible to cultivate more axial branches for June-bearing cultivars.

Some researchers in Japan have attempted before to remove the summer heat from culture media in high-bench culture systems (Komori and Kanke, 2002; Takaichi et al., 2001). Takaichi et al. (2001) were the first to introduce a system of cooling media by latent heat. We modified their system to make it simpler and more effective in evaporating water (Ikeda et al., 2006), and here we have demonstrated the practical use of the system for forcing culture of strawberries.

Ganmore-Neumann and Kafkafi (1983) found that a high root temperature $\left(32^{\circ} \mathrm{C}\right)$ decreased dry weight and leaf area. Utagawa et al. $(1989,1991)$ observed that a relatively high temperature $\left(23{ }^{\circ} \mathrm{C}\right)$ in the culture solution decreased root weight, nutrient absorbance, and photosynthesis rate in everbearing cultivars in a nutrient film technique system. Also, Lieten (1997) observed that higher root temperatures negatively affected vegetative development in his experiment ranging from 12 to $24{ }^{\circ} \mathrm{C}$.

With this system, because it was impossible to decrease the temperature of the medium below $23{ }^{\circ} \mathrm{C}$ when air temperature was high (Fig. 1), the roots of the runner plants could have been damaged by the high temperatures. However, under the cooling regime, the medium temperature rose above $23{ }^{\circ} \mathrm{C}$ for only a few hours a day, even in late summer (data not shown). Thus, the cooling system allowed the runner plants to maintain their growth. Another point is that the use of refrigeration for cooling media might not be 
practical because of the costs of electricity and equipment. Our system requires electricity only for pumping for irrigation and for operating the fan (apart from that needed for greenhouse climate control); it is simple and easy to handle (Ikeda et al., 2006).

In everbearing cultivars, fruits size and yield decrease above $23{ }^{\circ} \mathrm{C}$, although fruits number increases up to $27^{\circ} \mathrm{C}$ (Wagstaffe and Battey, 2004). Kumakura and Shishido (1995) also found 20 to $25{ }^{\circ} \mathrm{C}$ was optimum for the growth of four everbearing strawberry cultivars. However, June-bearing strawberry cultivars had a lower optimum temperature of $\approx 15{ }^{\circ} \mathrm{C}$ (Le Mière et al., 1998). Also, Lieten (1997) reported that higher root temperatures had a negative effect on fruit size in his experiment ranging from 12 to $24^{\circ} \mathrm{C}$. In our study, fruit number was fixed for both regime, and the average weight of fruits from primary axillary branch was $17.2 \mathrm{~g}$ under the cooling regime and $16.9 \mathrm{~g}$ for controls in the 2003 experiment, and $21.5 \mathrm{~g}$ under the cooling regime and $21.7 \mathrm{~g}$ for controls in the 2005 experiment; there was no significant difference in fruit weight between the regimes. Because the season at the time of fruit development on the primary axillary branch was already cold, fruit weight might not have been affected in the same way as flower-bud initiation.
In conclusion, cooling of the high-bench culture medium allowed the runner plants to be transplanted in late summer and accelerated flower-bud initiation on the primary axillary branch in forcing culture of strawberries.

\section{Literature Cited}

Ganmore-Neumann, R. and U. Kafkafi. 1983. The effect of root temperature and $\mathrm{NO}_{3}{ }^{-} / \mathrm{NH}_{4}{ }^{+}$ratio on strawberry plants. I. Growth, flowering, and root development. Agron. J. 75:941-947.

Ikeda, T., H. Kumakura, H. Hamamoto, T. Fujiwara, and T. Shimadu. 2006. Using latent heat of water evaporation to cool culture medium for high-bench strawberry culture. Acta Hort. 708:393-396.

Komori, H. and B. Kanke. 2002. The effect of yield increase by cool water use in the summer term on the summer-autumn growing strawberry on bench cultivation system. Tohoku Agric. Res. 55:237-238 (in Japanese).

Kumakura, H. and Y. Shishido. 1995. Effects of temperature and light conditions on flower initiation and fruit development in strawberry. Jpn. Agr. Res. Q. 29:241-250.

Le Mière, P., P. Hadley, J. Darby, and N.H. Battey. 1998. The effect of thermal environment, planting date and crown size on growth and development in Fragaria $\times$ ananassa Duch. cv. Elsanta. J. Hort. Sci. Biotechnol. 73:786-795.
Lieten, F. 1997. The effect of substrate temperature on strawberry performance on peat bags. Acta Hort. 450:501-504.

Morishita, M., T. Mochizuki, Y. Noguchi, K. Sone, and O. Yamakawa. 1997. 'Sachinoka', a new strawberry variety for forcing culture. Bull. Natl. Res. Inst. Veg., Ornam. Plants \& Tea, Jpn 12: 91-115 (in Japanese text with English summary).

Takaichi, M., K. Tanaka, and N. Nakashima. 2001. A simple method for cooling down the soil in bench culture of strawberry. FFTC (Taiwan) leaflet for agriculture, p. 2-3.

Utagawa, Y., T. Ito, and K. Gomi. 1989. Effects of root temperature on some physiological and ecological characteristics of strawberry plants 'Reiko' grown in nutrient solution. J. Jpn. Soc. Hort. Sci. 58:627-633 (in Japanese text with English summary).

Utagawa, Y., T. Ito, and K. Gomi. 1991. Effects of root temperature on the absorption of water and mineral nutrients by strawberry plants 'Reiko' grown hydroponically. J. Jpn. Soc. Hort. Sci. 59:711-717 (in Japanese text with English summary).

Wagstaffe, A. and N.H. Battey. 2004. Analysis of shade and temperature effects on assimilate partitioning in the everbearing strawberry 'Everest' as the basis for optimized long-season fruit production. J. Hort. Sci. Bio. 79:917-922.

Yamasaki, A., T. Yano, and H. Sasaki. 2003. Outof-season production of strawberry: Effects of a short-day treatment in summer. Acta Hort. 626:277-282. 